\title{
Preparation of Neodymium Metal by Pyro-Metallurgical Process Using Fluoride Salt
}

\author{
ALI Murad ${ }^{a^{*}}$, AZMAT lqbal ${ }^{b}$, WAQAR Ahmad ${ }^{c}$ \\ Institute of Industrial Control Systems, PO Box. 1398, Rawaplindi, Pakistan \\ aalimurad.uet@gmail.com, bazmatiqbal@yahoo.com, cwaqarxp@gmail.com
}

Keywords: Neodymium, Booster, Thermal Reduction

\begin{abstract}
The neodymium fluoride was reduced to metal by thermal reduction or pyrometallurgical process using calcium as reducing agent. Thermal reduction was carried out in a sealed reactions chamber in inert atmosphere with a nickel crucible having dry calcium fluoride lining. The stoichiometric mixture of neodymium fluoride and calcium metal chips were used in the form of pallets for pyro-metallurgical reactions. Small iodine was also added to increase heat available during ignition and to yield a lower melting and more fluid slag. The contents were heated electrically at a predetermined rate until ignition took place. The reaction was self-supporting and neodymium metal was obtained with fairly good efficiency.
\end{abstract}

\section{Introduction}

The rare earth elements constitute a group of fourteen members which are remarkably similar both in their physical and chemical properties and were grouped in the space allotted to lanthanum.

Rare earths are considered indispensable in modern industry because of their unique physicochemical properties. They are extensively used in new materials, energy conservation, environmental protection and IT devices as well as in military weapon systems. They have also significantly contributed to the miniaturization of electronic components, as used for cell phones and laptop computers. Rare earths are essential for green technologies such as wind powered turbines. They are widely applied in the automotive industry for catalysts, hybrid vehicle batteries, motors and generators, etc.[1].

The term pyro-metallurgy in chemical metallurgy refers to the use of high temperature reactions and process for the extraction and the refining of metals. The key parameters in pyro-metallurgy are temperature and environment. The benefits derived from the use of high temperatures include favourable chemical equilibrium and high reaction rates, and the possibility producing the metal in molten states or gaseous states which facilitates its ready separation from other reaction products [2].

The thermal reduction of rare earth halides/oxides is known to be possible only by using other reactive metals as reducing agent. These metals must have greater affinity for oxygen or halogens than the metals to be produced. In case of rare earth metals, reduction with element such as calcium, barium, magnesium, or aluminium gives only a mixture of oxides and metals, which are not easily separable. When chlorides are used, the results are comparatively better on theoretical ground due to high value of reducing enthalpies but not satisfactory on practical manner, as rare earth chlorides are difficult to prepare free from oxy-chlorides and also are highly hygroscopic [2].

Moldenhauer [3] prepared rare earth metals alloy from fluorides by reduction with calcium and obtained an alloy of cerium and $12 \%$ calcium. Mahn [4] prepared cerium, neodymium and gadolinium metals of $99 \%$ purity by addition of rare earth halides to molten magnesium metal at $800{ }^{\circ} \mathrm{C}$ with addition of chloride fluxes. The heating of the material removed the alloyed magnesium to within an average of $1 \%$. Contamination of the product metal by crucible attack was held to a minimum by conducting the reaction in molybdenum vessels. Gray [5] prepared high purity (94\%) cerium by reduction of cerium tri-fluoride with lithium, using iodine as a booster. The reductions were carried out in a steel bomb with external heating with efficiencies as high as $82 \%$. 
Ames Laboratory were able to prepare rare earth metals by the reduction of rare earth trichlorides with calcium metal in refractory-lined steel bombs [6]; this reaction did not generate enough heat to permit the reaction products to be in the liquid state long enough for the metal to separate. The simultaneous reaction of calcium and iodine was used as an additional heat source.

In the present study, it was investigated to prepare neodymium metal from neodymium fluoride by calcium reduction promoting self-supporting reaction without any external heating. The process was comparatively simple and economical to prepare rare earth metals by pyro-metallurgical technique.

Pyro-Metallurgy of Neodymium Fluoride - Theoretical Aspects. Table 1 gives heat evolved in the reaction of type shown:

$$
2(\mathrm{RE}) \mathrm{F}_{3}+3 \mathrm{M} \rightarrow 2 \mathrm{RE}+3 \mathrm{MF}_{2}
$$

where $\mathrm{RE}$ is for Neodymium and $\mathrm{M}$ is $\mathrm{Ca}$ or $\mathrm{Mg}$

Table 1 Reducing Metal Enthalpy.

\begin{tabular}{|c|c|c|c|c|}
\hline \multirow{2}{*}{$\begin{array}{c}\text { Rare earth } \\
\text { Halide }\end{array}$} & \multicolumn{4}{|c|}{ Reducing metal $\Delta \mathbf{H}_{298}$ in Kcal per gram atom of halogen } \\
\cline { 2 - 5 } & $\mathbf{C a}$ & $\mathbf{M g}$ & $\mathbf{K}$ & $\mathbf{A l}$ \\
\hline $\mathrm{NdCl}_{3}$ & -10.6 & +8.0 & -19.7 & +29.0 \\
\hline $\mathrm{NdF}_{3}$ & -8.4 & +5.1 & +2.1 & +31.1 \\
\hline
\end{tabular}

The data were computed by Quill. It can be seen that in the case of trichlorides, calcium and potassium give exothermic reactions, while neodymium flouride gives exothermic reaction only with calcium metal [7]. Hence, neodymium can be prepared by reacting a neodymium-bearing compound with a more active metal e.g $\mathrm{Ca}$. Some researchers were able to produce Neodymium metal, starting with chloride salt [8-10], therefore, not considered here.

The reaction of Neodymium fluoride with calcium metal is as follows:

$$
\begin{aligned}
& 2 \mathrm{NdF}_{3}+3 \mathrm{Ca} \rightarrow 2 \mathrm{Nd}+3 \mathrm{CaF}_{2} \\
& \Delta \mathrm{H}_{298}=-211.85 \mathrm{~kJ} / \mathrm{mole}(-10.6 \mathrm{Kcal} / \text { gram atom })
\end{aligned}
$$

This reaction is exothermic but heat evolved during the reaction is not enough to raise the temperature of the products to above $1412{ }^{\circ} \mathrm{C}$, the melting point of $\mathrm{CaF}_{2}$, even in an adiabatic reactor. The heat of fusion of $\mathrm{CaF}_{2}$ is $29.70 \mathrm{~kJ} / \mathrm{mole}$ and that of neodymium is $10.9 \mathrm{~kJ} / \mathrm{mole}$. The heat of reaction available would be $131.54 \mathrm{KJ} / \mathrm{mole}$. The expected temperature to which the system would rise as a result of reaction would be only $448{ }^{\circ} \mathrm{C}$. Hence additional heat input through booster or through preheating would be necessary. In the case of fluorides salt, the suitable booster material is iodine. Chlorates and other booster materials may cause oxidation of resulting metal.

Ahman et al. [6] has proved that iodine could be used as supplementary material. Furthermore iodine is converted into calcium iodide which would form a eutectic mixture with calcium fluoride and this mixture melts at lower temperature than pure calcium fluoride. Therefore, separation of metal and slag will be easier due to slag-metal density difference. Preheating may be used to initiate the reaction by locally heating a small portion of the charge to start the reaction. Dry material powder is mandatory. Water, if undesirable present in these initial source materials, has clearly to be removed prior to subjecting them to further processing. Some of the reasons for doing so may be cited as (i) the elimination of water reduces the weight of the material handled; (ii) if the material is to be charged in an electric furnace where the operating temperature is high $\left(\approx 1700{ }^{0} \mathrm{C}\right)$, the sudden release of water can cause charge blow off; (iii) in some case, the material becomes more reactive following water removal; and (iv) the presence of water can cause undesirable side reactions, leading to poor product quality and yield [2]. 


\section{Experimental Procedure}

In pyro-metallurgical reduction a well-blended mixture of neodymium fluoride, iodine and calcium metal chips is charged into a reduction chamber, which is lined with dry calcium fluoride powder. The Apparatus is shown schematically in Figure 1.

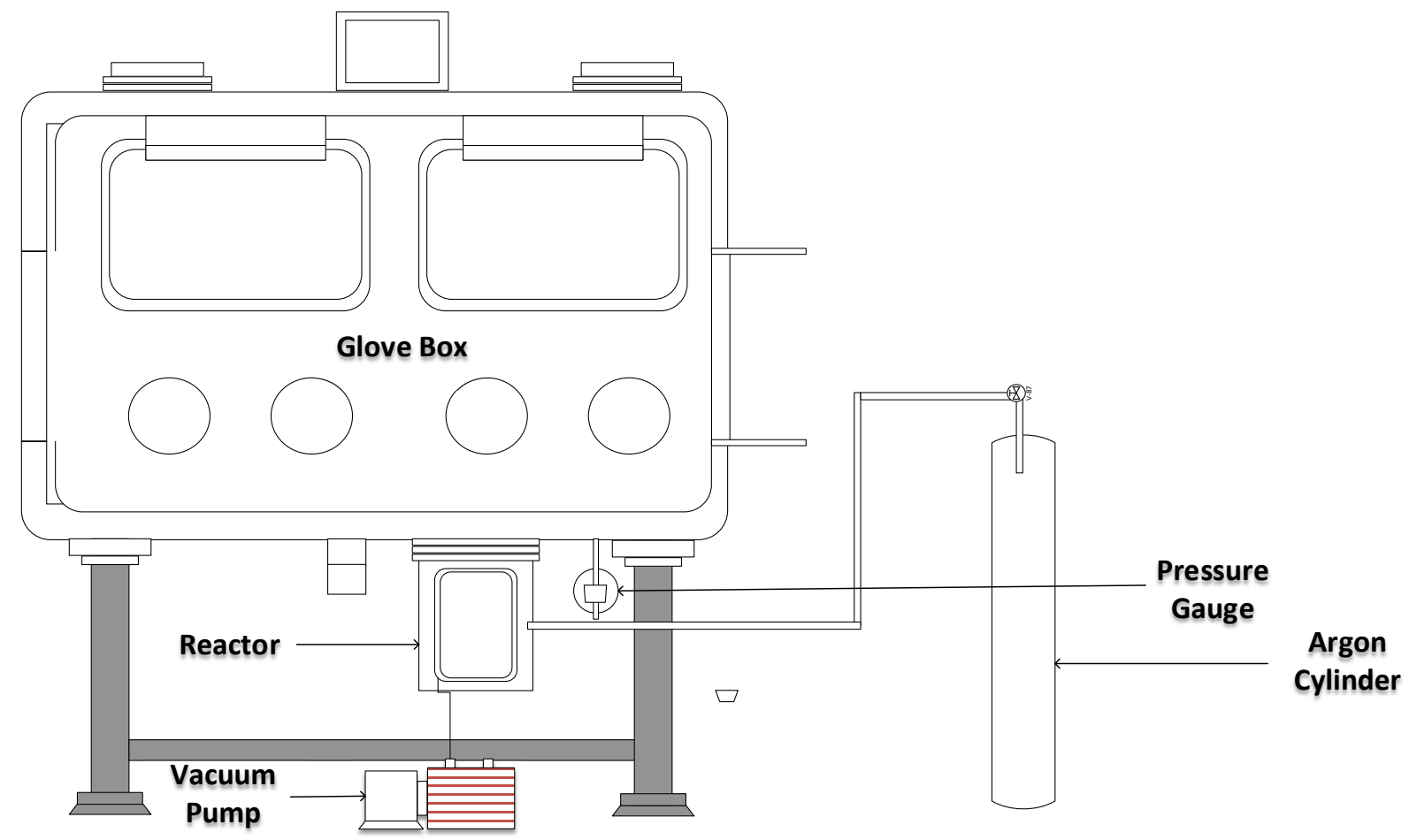

Fig. 1 Experimental assembly.

Calcium metal is a reactive metal special handling techniques were used. Most of the oxygen, nitrogen, carbon etc. if present as impurities in calcium will end up in the rare earth metal.

The purpose of the vacuum system was for providing clean atmosphere because air, dust and impure atmosphere may contaminate the system or may cause side reactions.

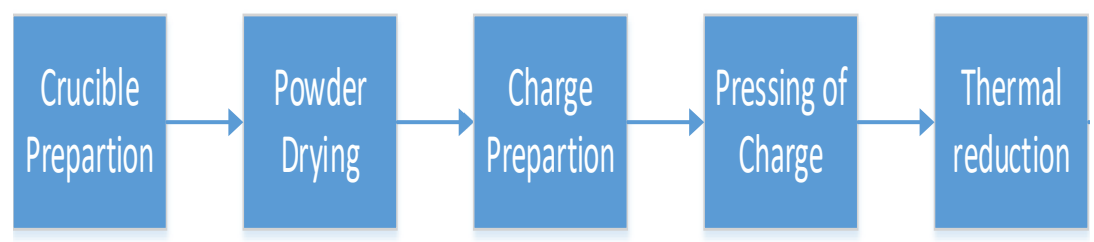

Fig. 2 Flow diagram of process.

Crucible Preparation:-In the reduction of $\mathrm{NdF}_{3}$ to Neodymium metal, Ni crucible lined with $\mathrm{CaF}_{2}$ was used and prepared as: $500 \mathrm{~g}$ of stock $\mathrm{CaF}_{2}$ powder was mixed with $50 \mathrm{ml}$ of distilled water. Three such mixture was prepared. Using a 100-ton press, three pellets of $\mathrm{CaF}_{2}$ were made at a pressure of $300 \mathrm{Kgf} / \mathrm{cm}^{2}$ in a specially designed die. The pellets were dried in a furnace at $400{ }^{0} \mathrm{C}$ for $2 \mathrm{hr}$. then baked at $1100{ }^{\circ} \mathrm{C}$ for $3 \mathrm{hr}$. The baked pellets were crushed in a jaw crusher to prepare the feed for the ball mill. The crushed material was grinded in a ball mill for $8 \mathrm{hr}$. This produces a fine $\mathrm{CaF}_{2}$ powder of average particle size less than 80 microns. $1300 \mathrm{~g}$ of fine $\mathrm{CaF}_{2}$ powder was mixed with $125 \mathrm{ml}$ of distilled water. With the help of a Perspex pattern, powder was pressed in the Ni crucible using hand hammers. The lined crucible was dried at $200{ }^{\circ} \mathrm{C}$ for $2 \mathrm{hr}$. and then baked at $700{ }^{\circ} \mathrm{C}$ for $3 \mathrm{hr}$. The use of pure and dry calcium fluoride as refractory material will advisable to avoid the contamination of produced metal.

Powder Drying. Neodymium fluoride powder was placed in the vacuum drying unit. The vacuum in the drying chamber was provided by cryo-pumping. The dryer was kept at $150{ }^{\circ} \mathrm{C}$ for $3 \mathrm{hr}$. The 
powder was then cooled to room temperature inside the dryer. Dry powder is vital for reduction otherwise it may cause charge blow off or may impure product due to side reactions.

Charge Preparation. The required amount of powder was weighed and transferred to a mixture jar of Pyrex or glass. Ca chips were weighed and added into the mixer. The mixer was than rotated electrically for about three minutes. The Ca chips should be cut and carefully selected in argon atmosphere to avoid oxidation. Chips size should be about 6-20 length $8 * 3 \mathrm{~mm}$. Experiments were performed with addition of iodine to the mixture of fluorides and calcium. Calcium chips needed should be 15 percent in excess of the quantity theoretically required to reduce the fluorides and to combine with iodine.

Pressing of Charge. In order to increase the quantity of metal which could be produced in a given size crucible, the mixed charge $\left(\mathrm{NdF}_{3}+\mathrm{Ca}\right.$ - chips + Iodine $)$ was placed in a die and subjected to a pressure of 100 ton. The set of specially designed dies and fixture are used for pressing purpose.

Thermal Reduction or Pyro-Metallurgical Process. Reduction of $\mathrm{NdF}_{3}$ to neodymium metal was carried out in a bomb sealed reactor. The Ni crucible lined with $\mathrm{CaF}_{2}$, was placed in the reactor. The pressed $\mathrm{NdF}_{3} / \mathrm{Ca}+$ iodine, block was placed in the crucible. The top portion of the block has a cavity to accommodate a tungsten filament. The filament was secured in place using the adjustable wedge type jaws which are then tightened to the electrical feed through. The filament should not touch the pressed block, however, the gap should not be more than $1 \mathrm{~mm}$. the reactor was closed and evacuated. Argon was introduced in the reactor until the pressure reaches $05 \mathrm{~kg} / \mathrm{cm}^{2}$. The evacuation/Argon flush cycle was repeated three times. Finally, argon was introduced until the internal pressure became one atmosphere. An automatic power supply was connected to the filament terminals and the voltage was increased slowly from $0-20$ volts in about 100 seconds. When the reaction was initiated the internal gauge pressure rises rapidly to about $0.4 \mathrm{Kg} / \mathrm{cm}^{2}$ and current in the circuit rises to about 25 amperes. The reaction proceeds and the power supply shuts itself off automatically. At least $8 \mathrm{hr}$. setting/cooling time was allowed. After cooling, the reactor was opened and the filament was taken out. The Ni crucible was removed from the system. The shrinkage of the crucible at the bottom was due to the contraction of ingot. The slag was removed from the crucible by washing in organic solvent.

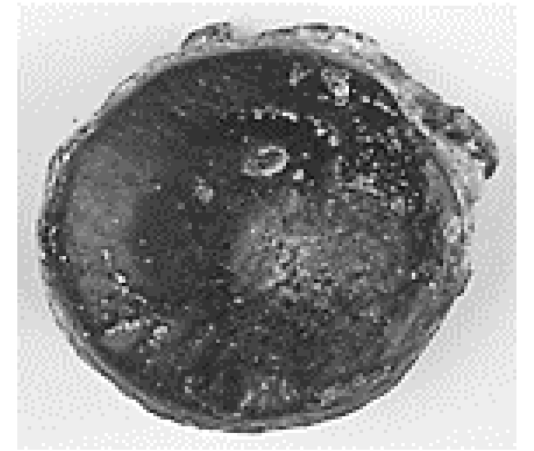

Fig. 3 Top surface of neodymium Ingot.

\section{Results \& Discussions}

Experiments conducted reveal that it was possible to prepare pure neodymium metal by thermal reduction using iodine booster.

Reaction become self-supporting due to booster. Efficiency was fairly good on a small scale and simplicity of the method was very attractive. Impurities present in fluorides salt results in poor yield. Water of crystallization, if present also effect efficiency [2] Commercial feasibility of this method depends on the prices of reagent iodine and calcium. The yield was calculated on the basis of total quantity of rare earth fluorides. The sample of metal ingot was analysed on scanning electron microscope equipped with energy dispersive spectrometer. The qualitative analysis is given in Table 2. 
Table 2 Qualitative analysis of metal ingot.

\begin{tabular}{|c|c|c|c|c|c|c|c|c|c|}
\hline & \multicolumn{7}{|c|}{ Chemical Composition (wt. \%) } \\
\cline { 2 - 11 } & C & O & Al & Ca & Sn & Sb & I & Nd & F \\
\hline \multirow{3}{*}{ Top surface } & $\begin{array}{c}19.7- \\
27\end{array}$ & $\begin{array}{c}13.8- \\
17.6\end{array}$ & $\begin{array}{c}0.05- \\
0.6\end{array}$ & $37-40$ & $1-2$ & $\begin{array}{c}3.7- \\
4.9\end{array}$ & $\begin{array}{c}6.7- \\
18\end{array}$ & $4-4.6$ & - \\
\hline $\begin{array}{l}\text { Cutting } \\
\text { Surface }\end{array}$ & - & - & $0.5-1.0$ & $\begin{array}{c}1.8- \\
3.8\end{array}$ & - & - & $\begin{array}{c}0.1- \\
0.8\end{array}$ & $95-97$ & - \\
\hline
\end{tabular}

Light metals e.g $\mathrm{Al}, \mathrm{Ca}, \mathrm{Sn}, \mathrm{Sb}$. accumulates on the surface of metal ingot due to density difference. Cutting surface confirm the major content of metal ingot as neodymium. The presence of calcium and iodine is obvious as both were used in excess quantity during reaction.

Efficiency may be increased by using pure and dry salt. Moisture contents is the major reason for decreasing yield of the reaction. Moisture can be of two types: free moisture and fixed moisture. Free moisture can easily be removed by providing heating system above the boiling temperature of water. Fixed moisture or water of crystallization is very difficult to remove. It requires $400-600{ }^{\circ} \mathrm{C}$ temperature along with suitable blanket of gaseous medium.

\section{Conclusion}

Small ingot of neodymium metal had been produced by pyro-metallurgical process of fluoride salt with calcium, using iodine as a booster in order to have a self-supporting reaction without any external heating.

Commercial feasibility of this method depends on the prices of calcium and iodine.

\section{Acknowledgement}

Author is thankful and obliged to Mr. Waheed Hussain for his technical assistance and guidance. Special thanks go to, Mr. Irfan Rasheed, Dr. Saeed Ahmed and Mr. Hafiz Hassan Shahzad for providing support needed to complete this research.

\section{References}

[1] C. Hurst, China's rare earth elements industry: What can the west learn? Institute for the Analysis of Global Security, Washington DC, 2010.

[2] C.K. Gupta, Chemical metallurgy: principles and practice, John Wiley \& Sons, 2006.

[3] F.H. Spedding, H.A. Wilhelm, W.H. Keller, D.H. Ahmann, A.H. Daane, C.C. Hach, R.P. Ericson, Production of pure rare earth metals, Indust. Eng. Chemi., 44 (1952) 553-556.

[4] F. Mahn, The Prepartion and Thermal Dissociation of Alloys of Magnesium with Cerium, Neodymium and Gadolinium, recherche science labs Bellvue, Paris, 1950.

[5] P. Gray, The production of pure cerium metal by electrolytic and thermal reduction processes, Trans. Inst. Min. Met., 61 (1952)

[6] K.A. Gschneidner Jr, Physical properties and interrelationships of metallic and semimetallic elements, in: Solid state physics, vol. 16, Elsevier, 1964, pp. 275-426.

[7] L.L. Quill, The chemistry and metallurgy of miscellaneous materials, in, Technical Information Service, AEC, 1955. 
[8] W. McGinnis, Heavy Rare Earth production, Technical Services, Department of Commerce, Washington 25, D.C.

[9] C. Bodsworth, The extraction and refining of metals, CRC Press, 1994.

[10] S. Liu, E. Subbarao, W. Wallace, The Science and Technology of Rare Earth Materials, Academic Press, New York, (1980). 